\title{
Analysis of the extrusion process using a flexible tool
}

\author{
Analiza procesu wytłaczania narzędziem elastycznym
}

MARIUSZ KRAKOWSKI JAROSŁAW BARTNICKI *
DOI: https://doi.org/10.17814/mechanik.2017.11.156
The possibility of detecting any errors during the construction phase, and not just during the tool manufacturing, increases the comfort of human work and minimizes the risk of unsatisfactory results.

In the presented analysis of the pressing process, it was decided to run simulations in the Simufact Forming software, which would allow to generate a grid of surface elements that accurately reproduce the assumed shape of the blank and the resulting extrudate.

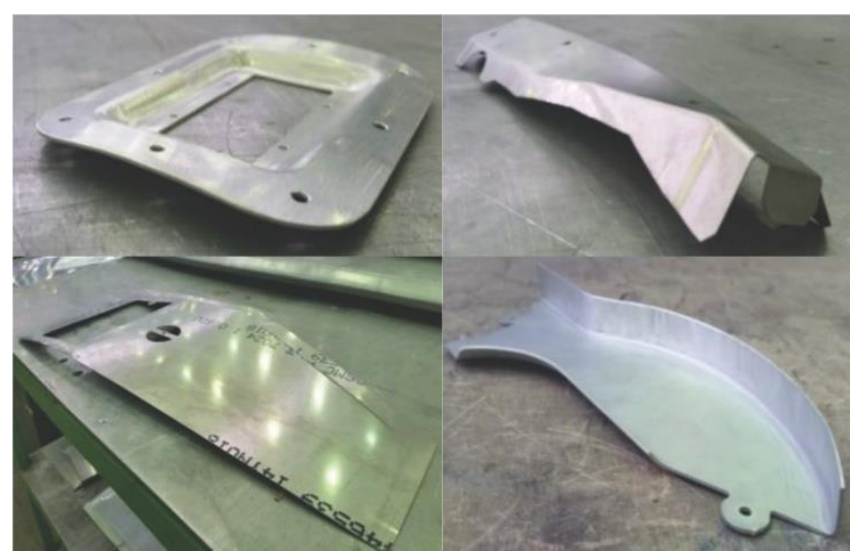

Fig. 1. Examples of products extruded with elastic stamps

\section{Realization of the pressing process with elastic tool}

The process of pressing with elastic tool in industrial conditions is most often based on the construction of a matrix on a sliding table, which moves along the guides, which prepared assembly - with shaping material, protective layers and elastic diaphragm - introduce into the working area of the press (fig. 2).

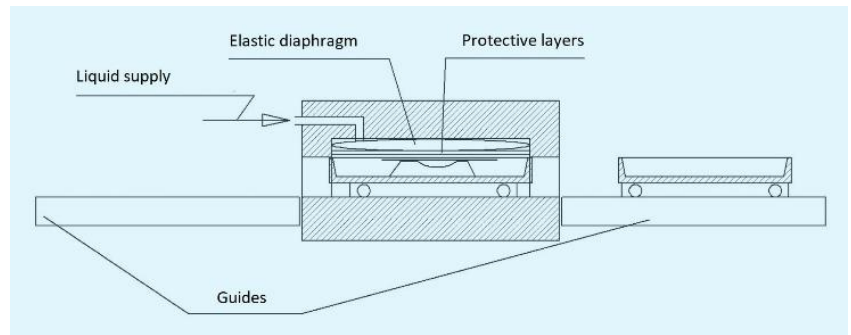

Fig. 2. Bottom of the table with visible guides

After this process has been prepared, the working fluid is applied at the appropriate pressure and the assumed forming time is maintained, which depends on many technological and construction factors (thickness and type of shaping material, assumed shape of the finished product, taking into account the pressing depth and bending radius, etc.).

\footnotetext{
* Mgr inż. Mariusz Krakowski, dr inż. Jarosław Bartnicki (j.bartnicki@ pollub.pl) - Katedra Komputerowego Modelowania i Technologii Obróbki Plastycznej, Politechnika Lubelska
} 
The introduction of composite metal sheets and solutions with spacers made of other materials into the aviation constructions made some products to be shaped after folding. Such processes are particularly difficult to implement due to the possibility of different elongation and bending of interconnected structural elements. In this case, additional insertion of internal stresses during the formation of the element is not recommended, and sometimes even dangerous. For this reason, the developed design solutions for elastic pressing tools sometimes include the need for annealing in the same instruments, where the blanks are attached to the embossing process. Fig. 3 shows subsequent stages of the elastic pressing process, and in fig. 4 - examples of hydraulic presses with a tunnel construction for the described process.

The Czech tunnel press from ZDAZ requires setting the matrix with the blank on the press table. When the table is moved to the work zone of the machine and the package is assembled into the work surface, the tool is formed by an elastic diaphragm, which separates the toolbox and the blanks from the work chamber with a bagshaped rubber filled with high pressure fluid. In the case of the Swedish AVURE tunnel press, this liquid reaches a working pressure of up to 800 bar. During practical implementation of the pressing processes with elastic tools in tunnel hydraulic presses, great technological and construction experience is required. One of the basic problems is to obtain products that fit within the assumed dimensional tolerances, which is not obvious at the deformation tool [5-9].
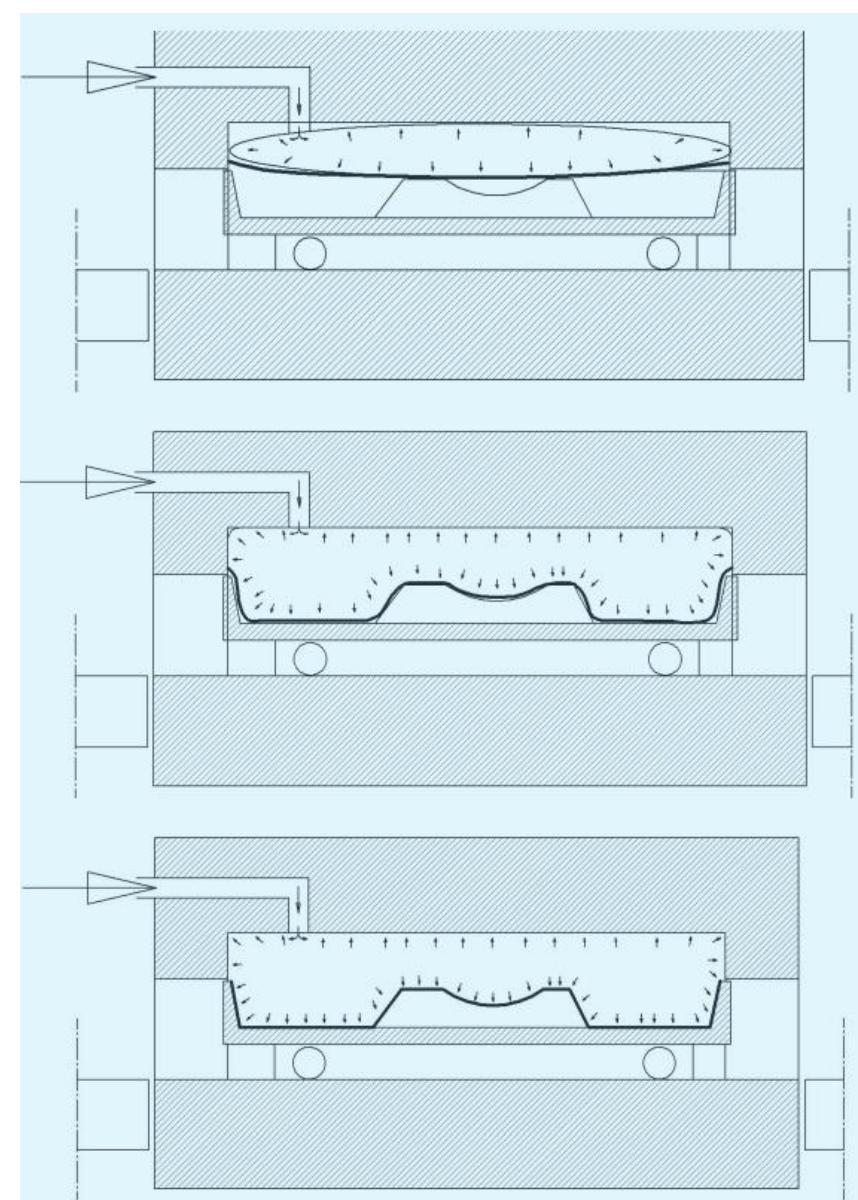

Fig. 3. Subsequent stages of the sheet pressing process with elastic tools
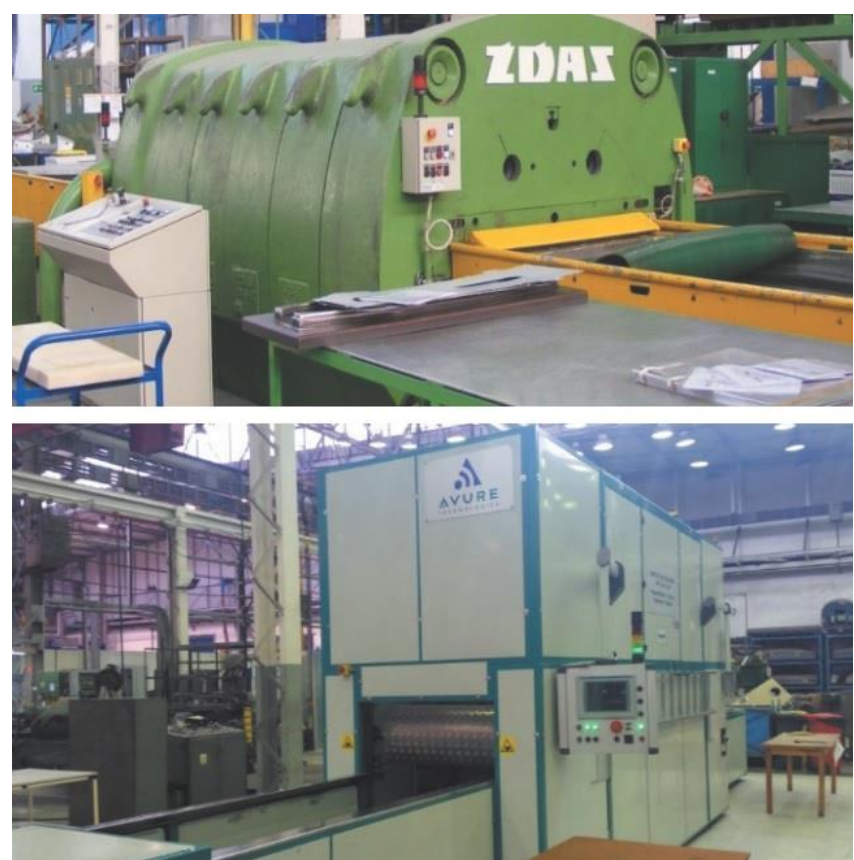

Fig. 4. Exemplary presses used to perform the pressing process with elastic tools

\section{Numerical analysis of the pressing process with elastic tool}

For numerical calculations of shaping processes using elastic tools, Simufact Forming software was selected, which gives wide opportunities of digitization the geometric model of the blank. Finishing of sheet metal in the Sheet Mesh module provided for their optimum distribution within the sheet thickness ( 3 or 5 elements in thickness were used in the calculation) and allowed to limit their number. Fig. 5 shows the numerical model of the tools used to perform the pressing of 2 parallel variable ribs in a sheet metal product. The main difficulty of the planned numerical simulation was introduction of the rubber material model, from which the stamp was made. The assumptions of the Young's modulus and Poisson's numbers were used to construct a linear model, which proved to be too simplistic, however. In addition, during the analysis, it was decided to enclose the elastic rubber element in a rigid casing, limiting the movement of the rubber to the sides. Only the geometric model was designed to provide adequate pressure, which allowed deformation of $0.5 \mathrm{~mm}$ thick titanium sheet. Selection of titanium resulted from the widespread use of this material in the aviation production, for example, for fire barriers or supports. In case of this type of products, the need to cut to the size, it is also necessary to make the ribs making these very light structures more rigid. Results of the initial calculations are shown in fig. 6 , where an example of the distribution of substitution stresses is given at the end of the shaping process.

In order to more accurately describe the conditions of the numerical analysis, it was necessary to build a model of the elastic material. Experimental studies were conducted using a specially prepared research instrument, which was built in the strength machine located in the laboratories of the Lublin University of Technology (fig. 7). After the compression tests of rubber stamps (made of commercially available material) of different heights $(50,100$ and $150 \mathrm{~mm})$ were determined, the dependence of strain-deformation, equation and graph for which is shown in fig. 8, was determined. 


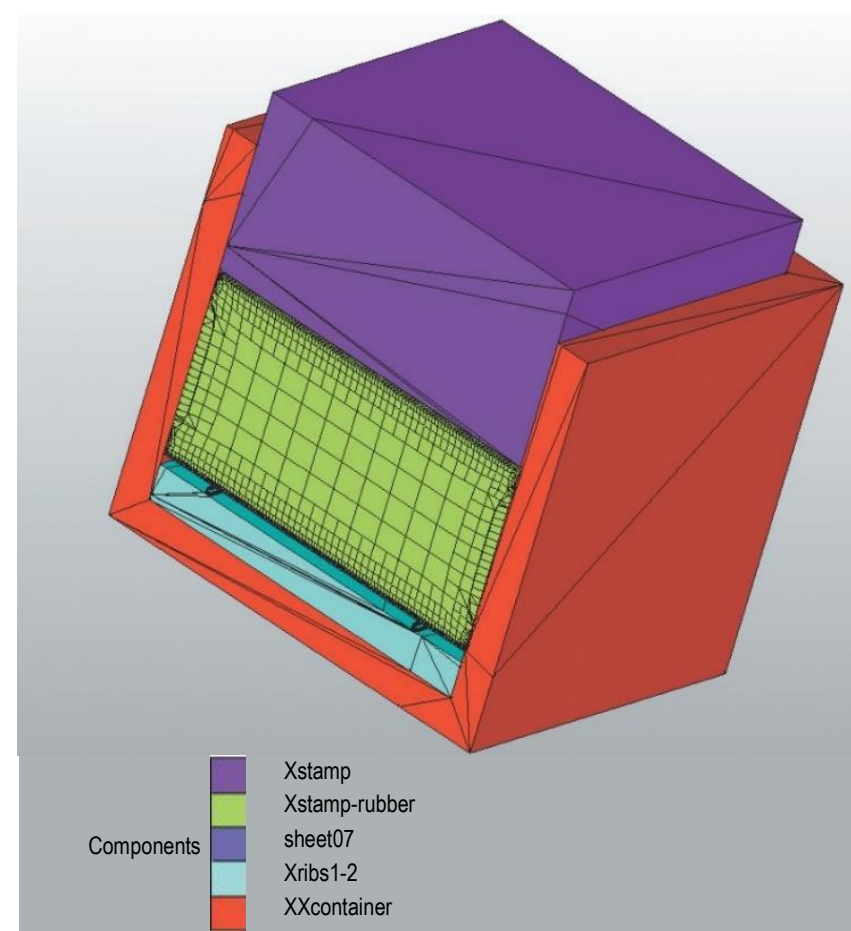

Fig. 5. Numerical model of the pressing process with elastic stamp without blank

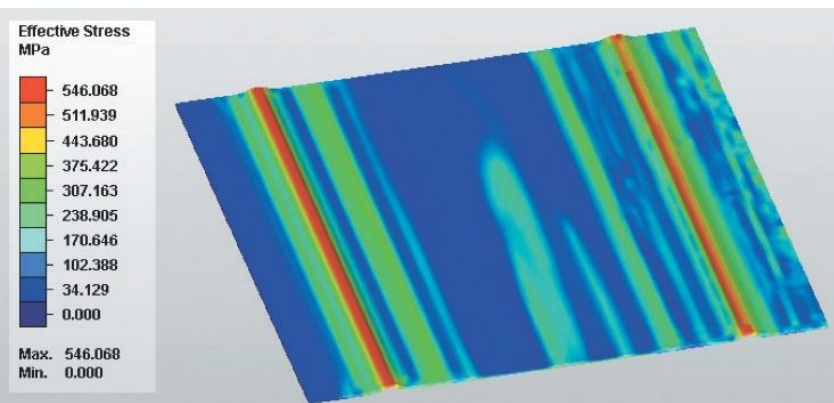

Fig. 6. Distribution of substitute stresses in elastic tool (Ti6Al4V material)
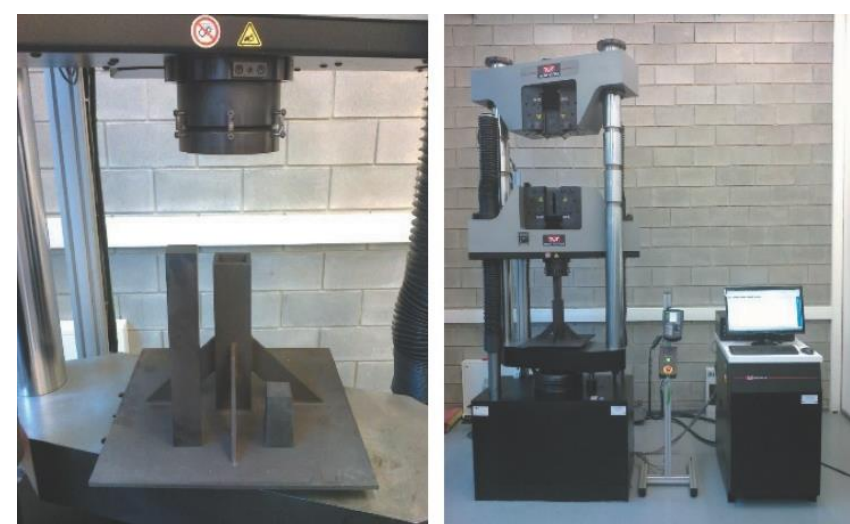

Fig. 7. Instrument with rubber and steel stamp (left) and its construction in the strength machine (right)

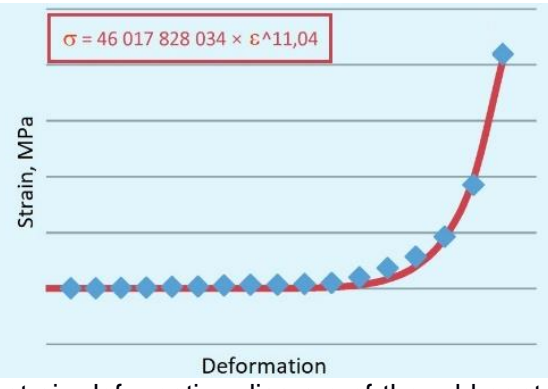

Fig. 8. The strain-deformation diagram of the rubber stamp used in industrial practice
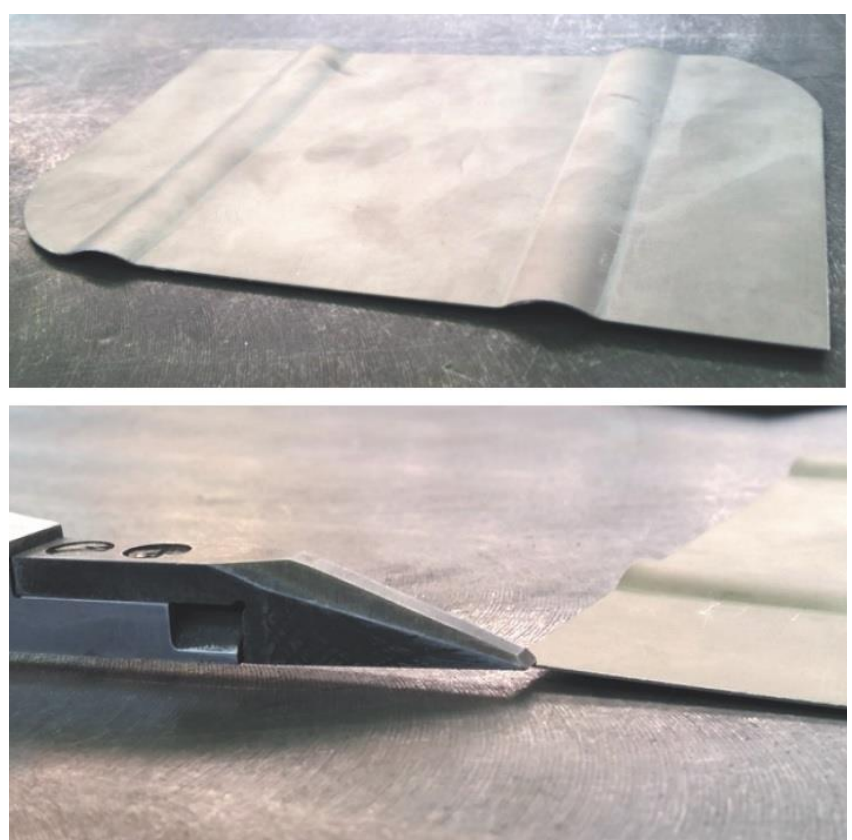

Fig. 9. Sample product with 2 ribs (top) and visible dimensional deviation to be eliminated (bottom)

Based on the calculations for a given material model, rib pressing processes on titanium sheets (fig. 9) are currently being analyzed - in this case, the most common problem is the folding and so-called loose fields. Unfortunately, each of the analyzed processes, when changing the elastic stamp material, requires additional testing to prepare data for the FEM software material models.

\section{Conclusions}

The application of FEM software at the stage of construction of the tools for the pressing process with elastic tools significantly simplifies the implementation procedure of this technology. Determining the correct shape of the rigid tool and choosing the characteristics of the elastic stamps with regard to the applied shaping forces is still an important technological problem. These issues are becoming increasingly difficult and less predictable as the complexity of the construction of components produced by this method increases. Further development of computational techniques greatly facilitates the design, and it is possible that new models of simulation software will include models of commercially available materials.

\section{REFERENCES}

1. Marciniak Z. „Konstrukcja tłoczników”. Warszawa: Ośrodek Techniczny A. Marciniak Sp. z o.o., 2002.

2. Klocke F. "Manufacturing Processes". 4. Forming RWTH, Aachen 2014.

3. Großmann K., Wiemer H., Hardtmann A., Penter L. Kriechenbauer S. "Adjusting the Contact Surface of Forming Tools in Order to Compensate for Elastic Deformations during the Process". 7th European LS-DYNA Conference Institute for Machine Tools and Control Engineering, TU Dresden, Dresden, Germany 2009.

4. Romanowski W.P. "Poradnik obróbki plastycznej na zimno". Warszawa: Wydawnictwo Naukowo-Techniczne, 1976.

5. Romanowski W.P. „Tłoczenie na zimno”. Warszawa: Wydawnictwo Naukowo-Techniczne, 1974.

6. Pater Z., Samołyk G. „Podstawy technologii obróbki plastycznej metali ". Lublin: Wydawnictwo Politechniki Lubelskiej, 2013.

7. Paquin J.R., Crowley R.E. "Die design fundamentals". Second edition. NY: Industrial Press Inc. 1987, s. 244.

8. Progressive Die Wizard Help, EDS 2003.

9. Stadnicki J., Wróbel I. "Evaluation of the influence of material model parameters on quality of designed drawpieces". Mechanik. 7 (2016). 